Jurnal Manajemen dan Bisnis, Volume 3, No. 1, Juli 2021

\title{
PENGARUH KOMPENSASI, KOMPETENSI, DAN MOTIVASI PADA PRODUKTIVITAS KERJA PEGAWAI PT. JASA MARGA (PERSERO) Tbk. CABANG PALIKANCI
}

\author{
Ni Wayan Fitriana Ayu Lestari ${ }^{1}$, Isti Riana Dewi ${ }^{2}$, Aan Kanivia ${ }^{3}$ \\ 1,2,3 Universitas Catur Insan Cendekia Cirebon \\ e-mail: niwayan.fitriana@cic.ac.id ${ }^{1}$, isti.riana@cic.ac.id ${ }^{2}$, aanwaroka@gmail.com ${ }^{3}$
}

\begin{abstract}
There is job dissatisfaction that some employees at PT. Jasa Marga (Persero) Tbk. The Palikanci branch resulted in low work productivity. This study took a sample of 58 employee respondents. The technique of taking using purposive sampling was collected through a questionnaire instrument aimed to determine the effect of compensation, competence, and motivation on work productivity. The analysis technique uses multiple regression analysis. It was found that there was a positive and significant influence between the variables of compensation, competence, motivation on work productivity at PT. Jasa Marga (Persero) Tbk. Palikanci branch either partially or simultaneously. So it is necessary to pay attention to the company so that it can pay more attention to the amount of compensation given and appreciation of employee competence to increase work productivity. Likewise, high motivation must be evaluated to increase work productivity which will help the company achieve its goals.
\end{abstract}

Keyword: compensation, competence, motivation, work productivity

\begin{abstract}
ABSTRAK
Adanya ketidakpuasan kerja yang beberapa pegawai di PT. Jasa Marga (Persero) Tbk. Cabang Palikanci mengakibatkan rendahnya produktivitas kerja. Penelitian ini mengambil sampel 58 responden pegawai. Teknik pengambilnaya dengan, purposive sampling dikumpulkan melalui instrumen kuisioner, betujuan untuk mengetahui pengaruh kompensasi, kompetensi, dan motivasi terhadap produktivitas kerja. Teknik analisisnya menggunakan analisis regresi berganda. Ditemukan terdapat pengaruh positif dan signifikan antara variabel kompensasi, kompetensi, motivasi terhadap produktivitas kerja di PT. Jasa Marga (persero) tbk. Cabang Palikanci baik secara parsial maupun simultan. Maka perlu menjadi perhatian perusahaan agar dapat lebih memperhatikan besarnya kompensasi yang diberikan serta apresiasi kompetensi pegawai untuk meningkatkan produktivitas kerja. Sama halnya dengan motivasi yang tinggi harus dievaluasi guna meningkatkan produktivitas kerja yang akan membantu perusahaan dalam mencapai tujuannya.
\end{abstract}

Kata kunci: kompensasi, kompetensi, motivasi, produktivitas kerja

Korespondensi: Isti Riana Dewi, S.E., M.M. Universitas Catur Insan Cendekia Cirebon. Jl. Kesambi no. 202, Drajat, Kesambi, Kota Cirebon, 45133. Email: isti.riana@cic.ac.id 
Jurnal Manajemen dan Bisnis, Volume 3, No. 1, Juli 2021

\section{PENDAHULUAN}

Di Indonesia terdapat masalah yang cenderung terjadi. Penanganan terhadap rendahnya kualitas sumber daya manusia di suatu perusahaan. Sumber daya manusia yang jumlahnya besar apabila dapat diberdayakan secara efektif akan bermanfaat untuk menunjang gerak laju pembangunan nasional yang berkelanjutan. Banyaknya sumber daya manusia yang dimiliki saat ini menuntut manajemen perusahaan besar di Indonsia untuk berfikir bagaimana agar dapat memanfaatkan sumber daya manusia secara optimal. Sehingga terdapat pegawai yang qualified. Pegawai yang qualified didapatkan dengan jenjang pendidikan yang sesuai, tersedianya fasilitas yang memadai, serta adanya lapangan pekerjaan.

Seiring dengan perkembangan zaman, maka semakin lama dunia usaha semakin kompleks. Perubahan-perubahan yang berlangsung dengan begitu cepatnya pada lingkungan dimana perusahaan itu berada, maupun perubahan-perubahan dalam tingkat nasional, regional bahkan tingkat dunia internasional. Hanya perusahaanperusahaan yang memiliki perencanaan yang baik dan keunggulan kompetitif yang akan mampu bersaing secara kompetitif. Seiring dengan persaingan yang terjadi dan perkembangan perekonomian yang dinamis, kesuksesan suatu perusahaan tergantung pada pengelolaan perusahaan itu sendiri.

Salah satunya PT. Jasa Marga (persero) tbk. Cabang Palikanci yang merupakan Badan Usaha Milik Negara yang bergerak dibidang jasa penyediaan jalan tol. Di dalam PT. Jasa Marga (persero) tbk. Cabang Palikanci tentu terdapat tantangan dalam beroperasional. Banyak terjadi permasalahan didalam perusahaan itu. Khususnya masalah sumber data manusia. Terdapat beberapa karyawan yang memiliki performa yang kurang baik yang dilihat dari keterlambatan absensi, menurunya prestasi atau produktivitas karyawan. Setelah dilakukan wawancara dengan salah satu staf human resource PT. Jasa Marga (persero) tbk. Cabang Palikanci, hal itu terjadi karena ketidakpuasan bekerja yang juga disebabkan kurangnya dorongan sesama rekan kerja.

Pada umumnya dalam diri seorang pekerja ada dua hal yang penting dan dapat memberikan motivasi atau dorongan yaitu masalah kompensasi dan ekspektasi. Hal itu sebagai imbal jasa dari perusahaan kepada karyawan yang telah memberikan kontribusinya selalu menjadikan sebagai 
Jurnal Manajemen dan Bisnis, Volume 3, No. 1, Juli 2021

ukuran puas atau tidaknya seseorang dalam menjalankan tugasnya atau pekerjaannya. Namun , pemberian kompensasi dapat berdampak negatif apabila dalam pelaksanaannya tidak adil. Untuk itu, pemberian kompensasi kepada pegawai harus adil dan transparan sesuai porsinya masingmasing. Program kompensasi yang baik akan bermanfaat bagi perusahaan karena mencerminkan upaya organisasi untuk mempertahankan sumber daya manusia untuk loyal dan berkomitmen pada perusahaan.

Kompetensi juga perlu diperhatikan karena berhubungan erat dengan kualitas sumber daya manusia yang ada, baik kemampuan fisik maupun non fisik. Perbaikan kualitas pegawai yang dilakukan berperan dalam meningkatkan kemampuan professional pegawai. Kompetensi merupakan faktor mendasar yang dimiliki seseorang yang mempunyai kemampuan lebih yang diperlukan untuk melakukan pekerjaan dengan kualitas baik untuk membantu organisasi untuk menciptakan budaya kinerja tinggi (Rahayuningsih. \& Maelani., 2018). Kompetensi berada pada kepribadaian individu yang melekat dan dapat diprediksi untuk berbagai tugas pekerjaan.

Faktor yang paling penting dan menentukan terhadap keberhasilan dan pencapaian suatu perusahaan adalah motivasi dari karyawan untuk berkerja (Candra \& Fatimah, 2020). Sumber daya yang pontensial akan menentukan keberhasilan. Dan tentu di butuhkan pemimpin perusahaan yang mampu menumbuhkan suatu motivasi kerja kepada karyawan. Motivasi pada intinya adalah sebuah perilaku yang memiliki orientasi pada tujuan. Jadi motivasi merupakan hal yang paling pokok dalam pencapaian tujuan yang telah ditetapkan. Pada dasarnya motivasi di jabarkan dua macam yaitu : motivasi internal (kepuasan kerja) dan motivasi eksternal (finansial) yang kedua faktor tersebut adalah faktor yang saling berkaitan.

Jika kompensasi, kompetensi dan motivasi lebih diperhatikan oleh manager. Maka apabila seorang karyawan merasa puas dan senang terhadap pekerjaan, ia jarang mengeluh dan cenderung meningkatkan kualitas hasil kerjanya, artinya produktivitas kerja karyawan akan meningkat(Aguk Sridaryono, 2019). Hal itu menguntungkan bagi perusahaan. Manajer perusahaan yang 
Jurnal Manajemen dan Bisnis, Volume 3, No. 1, Juli 2021

dapat berperan aktif seperti itu didalam pengambilan keputusan atau kebijakan dengan melihat kemungkinan dan kemampuan serta kesempatan untuk menilai karyawan yang baik dalam melakukan pekerjaannya. Produktivitas kerja yang baik akan mempunyai pengaruh yang dominan terhadap perusahaan dalam pencapaian tujuan.

\section{TINJAUAN PUSTAKA}

\section{Kompensasi}

Kompensasi adalah pendapatan seseorang yang diperoleh dari perusahaan dari hasil pekerjaan yang sudah dilakukan pegawai sebagai bentuk apresiasi perusahaan. Sedangkan menurut yang lain, kompensasi merupakan segala pendapatan yang berbentuk uang, barang langsung atau tidak langsung sebagai imbalan atas jasa yang diberikan kepada perusahaan terhadap karyawan (Santoni \& Suana, 2018). Ada tiga bentuk lain seperti gaji, upah dan upah insentif. Gaji merupakan alas jasa yang dibayar secara periodik kepada karyawan tetap serta mempunyai jaminan yang pasti (Candra \& Fatimah, 2020). Kemudian, upah sendiri merupakan bentuk balasan dari perusahaan pada pekerja yang berpedoman pada perjanjian yang telah disepakati.
Sedangkan upah insentif dapat dikatan sebagai bonus pada pekerja tertentu yang berhasil menghasilkan suatu prestasi.

\section{Kompetensi}

Kompentensi merupakan potensi dalam diri pegawai yang dapat membantu perusahaan dalam memperoleh keuntungan yang optimal. Kompetensi dikatakan salah satu faktor yang mempengaruhi kinerja. Jika kompetensi diperhatikan mampu menghasilkan budaya kinerja yang baik. Banyaknya kompetensi yang digunakan oleh sumber daya manusia akan meningkatkan kinerja (Rahayuningsih. \& Maelani., 2018). Selain itu kompetensi kerja juga merupakan salah satu faktor yang sangat penting dan berpengaruh terhadap keberhasilan seseorang di dalam melaksanakan suatu pekerjaan, karena kompetensi merupakan potensi yang ada dalam diri seseorang unuk berbuat sesuatu, sehingga memungkinkan seseorang untuk dapat melakukan pekerjaan ataupun tidak dapat melakukan pekerjaan tersebut (Aguk Sridaryono, 2019). Peneliti terdahulu juga menemukan jika kompetensi tinggi maka diikuti dengan produktivitas kerja yang tinggi (Ngatemin \& Arumwanti, 2019) (Aguk Sridaryono, 2019). 
Jurnal Manajemen dan Bisnis, Volume 3, No. 1, Juli 2021

\section{Motivasi}

Dalam motivasi didasarkan dari Maslow's Needs Hierarchy Theory. Teori ini dikemukakan oleh Abraham Maslow mengemukakan a theory of human motivation atau teori Motivasi Hierarki kebutuhan Maslow. Teori ini menjelaskan hierarki kebutuhan seseorang dalam berperilaku dan bekerja. Dorongan yang ada untuk bekerja menyebabkan seseorang mampu memenuhi berbagai macam kebutuhan. Maslow menjelaskan tahapan kebutuhan yang diharapkan oleh seseorang secara bertahap. Jika kebutuhan fisik terpenuhi yang merupakan kebutuhan tingkat pertama, maka akanmuncul rasa ingin memenuhi kebutuhan keamanan yaitu kebutuhan tingkat dua. Begitu pula seterusnya sampai dengan mencapai tingkat lima yaitu kebutuhan aktualisasi diri. Didukung oleh penelitian terdahulu yang menjelaskan pengaruh positif motivasi terhadap produktivitas kerja pegawai (Santoni \& Suana, 2018) (Oh \& Novita, 2019) (Peni \& Suyoko, 2019) (Candra \& Fatimah, 2020)(Djuhara, 2014).

\section{Produktivitas Kerja}

Produktivitas kerja merupakan kinerja pegawai terhadap perusahaan yang mampu meningkatkan keuntungan perusahaan karena dianggap membantu tercapainya tujuan peruasahaan. Produktivitas kerja juga merupakan bentuk perencanaan dan pengembangan industri yang akan berkontribusi bagi pengembangan ekonomi nasional secara tidak langsung (Oh \& Novita, 2019). Produktivitas sebagai pengukuran atas kuantitas dan kualitas dari pekerja yang diselesaikan, dengan mempertimbangkan biaya dari sumber daya yang digunakan (Peni \& Suyoko, 2019). Ditemukan oleh peneliti terdahulu yang menjelaskan terdapat beberapa faktor-faktor yang mepengaruhi produktivitas kerja seperti besarnya kompensasi, kompetensi dan motivasi pegawai (Asneli, Haryani, \& Satriadi, 2018). Adapun model penelitian ini dapat dilihat pada gambar 1 .

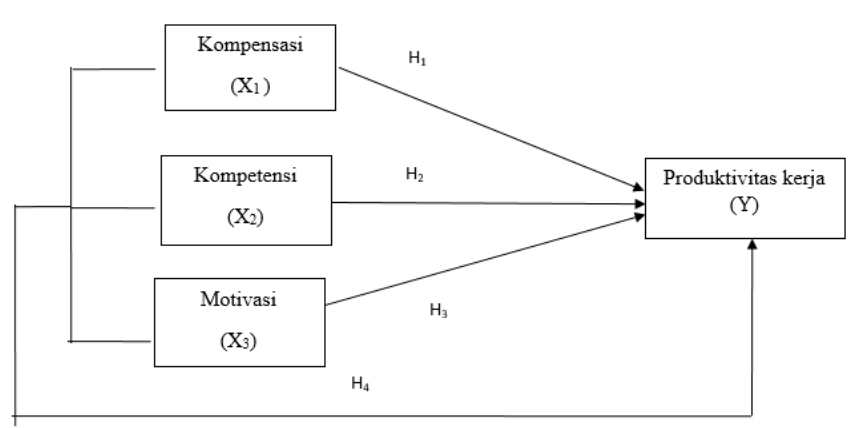

Gambar 1. Model Penelitian

\section{Keterangan :}


Jurnal Manajemen dan Bisnis, Volume 3, No. 1, Juli 2021

$\mathrm{H}_{1}$ :Terdapat pengaruh positif antara kompensasi $\quad\left(\mathrm{X}_{1}\right) \quad$ terhadap produktivitas kerja (Y).

$\mathrm{H}_{2}$ :Terdapat pengaruh positif antara kompetensi $\left(\mathrm{X}_{2}\right)$ terhadap produktivitas $\operatorname{kerja}(\mathrm{Y})$.

$\mathrm{H}_{3}$ :Terdapat pengaruh positif antara motivasi $\left(\mathrm{X}_{3}\right)$ terhadap produktivias kerja (Y).

$\mathrm{H}_{4}$ :Terdapat pengaruh positif antara kompensasi $\left(\mathrm{X}_{1}\right)$, kompentensi $\left(\mathrm{X}_{2}\right)$, dan motivasi $\left(\mathrm{X}_{3}\right)$ secara bersama-sama terhadap Produktivitas kerja (Y).

\section{METODE PENELITIAN}

Penelitian ini di lakukan pada PT. Jasa Marga (Persero) Tbk. cabang Palikanci yang beralamatkan di Jalan Jenderal Sudirman No.138 Ciperna, Cirebon Selatan. Waktu Penelitian terhitung dari bulan Januari sampai dengan bulan April 2021. Metode penelitian ini yaitu kuantitatif. Teknik analisis menggunakan regresi linear berganda dengan alat bantu SPSS sebagai pendukungnya. Pengambilan sampel dengan menyebar instrument kuisioner kepada responden (Dewi, 2020). Sebelum analisis regresi, dilakukan terlebihdahulu uji instrument, uji validitas, uji reliabilitas, uji normalitas, uji heteroskedastisitas, dan uji multikolinearitas.

Responden ditentukan dengan purposive sampling dan rumus slovin yaitu dari seluruh pegawai kantor Jasa Marga (Persero) Tbk.Cabang Palikanci sebanyak 172 pegawai, sehingga jumlah yang diteliti sebanyak 63 pegawai. Responden 63 orang karyawan dari 63 kuesioner yang disebarkan, peneliti memperoleh 58 kuesioner yang layak untuk disertakan dalam penelitian karena terdapat 5 kuesioner yang tak kembali. Jadi, jumlah sampel yang di terima sebanyak 58 karyawan. Dalam mengidentifikasi karakteristik responden dalam penelitian ini, peneliti membaginya dalam beberapa kategori diantaranya: jenis kelamin, usia, dan pendidikan.

\section{HASIL DAN PEMBAHASAN}

\section{Klasifikasi Responden}

Responden yang diambil berjumlah 58 responden. Karakteristik responden karyawan PT. Jasa Marga Persero Tbk. Cabang Palikanci dalam penelitian ini menurut jenis kelamin ditunjukan dalam Tabel 1. Dalam tabel 1 umlah pria lebih besar daripada wanita. Hal ini di karenakan bahwa perusahaan ini memeiliki pekerjaan yang 
Jurnal Manajemen dan Bisnis, Volume 3, No. 1, Juli 2021

cukup berat untuk para wanita sehingga karyawan yang dipekerjakan lebih banyak pria karena dinilai memiliki stamina yang lebih baik. Sehingga responden yang paling banyak adalah pria yaitu 48 orang atau $82,6 \%$ dari total responden.

Tabel 1. Klasifikasi Responden Berdasar Gender

\begin{tabular}{ccc}
\hline $\begin{array}{c}\text { Jenis } \\
\text { Kelamin }\end{array}$ & $\begin{array}{c}\text { Jumlah } \\
\text { Responden }\end{array}$ & $\begin{array}{c}\text { Presentase } \\
(\%)\end{array}$ \\
\hline Pria & 48 & $82,6 \%$ \\
Wanita & 10 & $17,4 \%$ \\
Jumlah & 58 & $100 \%$ \\
\hline
\end{tabular}

Sumber: hasil kuesioner diolah tahun 2021

Karakteristik pada pegawai PT. Jasa Marga Persero Tbk. Cabang Palikanci yang sebagai responden dalam penelitian berdasar pada usia dirangkum dalam Tabel 2. Terlihat bahwa responden paling sedikit yang menjadi objek penelitian ini terdiri dari usia kurang dari 25 tahun sebanyak 7 orang atau 12,1\% dari jumlah seluruh responden. Sedangkan responden yang paling banyak yaitu usia antara 36-45 tahun sebanyak 26 orang atau $44,8 \%$ dari jumlah seluruh responden. Hal itu dikarenakan rata-rata pekerja PT. Jasa Marga Persero Tbk. Cabang Palikanci yang sudah memasuki usia 36 tahun sudah berkeluarga cenderung memilih bertahan daripada mencari pekerjaan baru yang akan menyulitkan mereka bersaing dengan calon pegawai yang lebih muda.

Tabel 2. Klasifikasi Responden Berdasar Umur

\begin{tabular}{ccc}
\hline Usia & $\begin{array}{c}\text { Jumlah } \\
\text { Responden }\end{array}$ & Presentase (\%) \\
\hline$<25$ tahun & 7 & $12,1 \%$ \\
$25-35$ tahun & 13 & $22,4 \%$ \\
$36-45$ tahun & 26 & $44,8 \%$ \\
$>46$ tahun & 12 & $20,7 \%$ \\
Jumlah & 58 & $100 \%$ \\
\hline
\end{tabular}

Sumber: hasil kuesioner diolah tahun 2021

\section{Uji Validitas}

Tabel 3 menjelaskan bahwa nilai Corrected Item-Total Correlation lebih beasar $r$ tabel artinya semua pernyataan untuk variabel kompensasi, kompetensi, motivasi dan produktivitas kerja adalah valid. Maka dapat disimpulkan bahwa semua pernyataan instrumen variabel kompensasi, kompetensi, motivasi dan produktivitas kerja valid untuk dapat digunakan dalam proses analisis data.

Tabel 3. Uji Validitas

\begin{tabular}{|c|c|c|c|c|}
\hline $\begin{array}{c}\text { Variab } \\
\text { el }\end{array}$ & $\begin{array}{c}\text { Butir } \\
\text { peryataa } \\
n\end{array}$ & $\begin{array}{c}\text { Correc } \\
\text { ted } \\
\text { Item- } \\
\text { Total } \\
\text { Correl } \\
\text { ation }\end{array}$ & $\begin{array}{c}\mathrm{r}_{\text {tabel }}(5 \\
\%)\end{array}$ & $\begin{array}{c}\text { Keteran } \\
\text { gan }\end{array}$ \\
\hline \multirow{6}{*}{$\begin{array}{c}\text { Komp } \\
\text { ensasi } \\
(\mathrm{X} 1)\end{array}$} & $\mathrm{X} 1.1$ & 0.335 & 0,257 & Valid \\
\hline & $\mathrm{X} 1.2$ & 0.290 & 0,257 & Valid \\
\hline & $\mathrm{X} 1.3$ & 0.401 & 0,257 & Valid \\
\hline & X1.4 & 0.520 & 0,257 & Valid \\
\hline & X1.5 & 0.335 & 0,257 & Valid \\
\hline & X2.1 & 0.461 & 0,257 & Valid \\
\hline
\end{tabular}


Jurnal Manajemen dan Bisnis, Volume 3, No. 1, Juli 2021

\begin{tabular}{ccccc}
\hline & X2.2 & 0.320 & 0,257 & Valid \\
Komp & X2.3 & 0.268 & 0,257 & Valid \\
etensi & X2.4 & 0.398 & 0,257 & Valid \\
(X2) & X2.5 & 0.422 & 0,257 & Valid \\
& X2.6 & 0.279 & 0,257 & Valid \\
& X3.1 & 0.384 & 0,257 & Valid \\
& X3.2 & 0.346 & 0,257 & Valid \\
Motiv & X3.3 & 0.302 & 0,257 & Valid \\
asi & X3.4 & 0.410 & 0,257 & Valid \\
(X3) & X3.5 & 0.363 & 0,257 & Valid \\
& X3.6 & 0.390 & 0,257 & Valid \\
Produ & Y.1 & 0.360 & 0,257 & Valid \\
ktivita & Y.2 & 0.658 & 0,257 & Valid \\
s & Y.3 & 0.311 & 0,257 & Valid \\
Kerja & Y.4 & 0.428 & 0,257 & Valid \\
(Y) & Y.4
\end{tabular}

Sumber: hasil kuesioner diolah tahun 2021

\section{Uji Reliabilitas}

Uji reliabilitas bertuuan untuk mengetahui adanya konsistensi alat ukur dalam penggunaannya. Jik variabel dikatakan reliabel artinya variabel tersebut yang bila digunakan beberapa kali dalam measure suatu objek terntentu yang sama cenderung akan menghasilkan data yang sama pula. Sedangkan suatu instrumen dapat dikatakan reliabel apabila memenuhi kriteria seperti memiliki nilai Cronbach's Alpha lebih dari 0,60. Dalam hal ini sama dengan yang ditemukan di output SPSS tabel 4 dijelaskan bahwa variabel kompensasi, kompetensi, motivasi dan produktivitas kerja adalah realibel.

Tabel 4. Uji Reliabilitas

\begin{tabular}{ccc}
\hline Variabel & $\begin{array}{c}\text { Cronbach's } \\
\text { Alpha }\end{array}$ & $\begin{array}{c}\mathrm{N} \text { of } \\
\text { Items }\end{array}$ \\
\hline
\end{tabular}

\begin{tabular}{ccc}
\hline Kompensasi & 0.614 & 5 \\
Kompetensi & 0.616 & 6 \\
Motivasi & 0.632 & 6 \\
Produktivitas & 0.647 & 4 \\
Kerja & & \\
\hline
\end{tabular}

Sumber: hasil kuesioner diolah tahun 2021

\section{Analisis Regresi Berganda}

Analisis dengan regresi berganda bertujuan untuk mengetahui seberapa besar pengaruh dari variabel-variabel independent secara bersamaan terhadap variabel dependent. Seperti yang sudah dijelaskan sebelumnya bahwa dalam penelitian ini variabel Kompensasi $\left(\mathrm{X}_{1}\right)$, Kompetensi $\left(\mathrm{X}_{2}\right)$ dan Motivasi $\left(\mathrm{X}_{3}\right)$ sebagai variabel independen yang berpengaruh terhadap variabel Produktivitas Kerja (Y) sebagau variabel dependen. Berikut ini adalah hasil analisis regresi berganda dengan menggunakan program SPSS: 
Jurnal Manajemen dan Bisnis, Volume 3, No. 1, Juli 2021

Tabel 5. Output Analisis Regresi Linear

Berganda

\begin{tabular}{|c|c|c|c|c|c|c|}
\hline \multicolumn{7}{|c|}{ Coefficients $^{\mathrm{a}}$} \\
\hline & & & & $\begin{array}{l}\text { Standardi } \\
\text { zed }\end{array}$ & & \\
\hline & & $\begin{array}{r}\text { Unstanc } \\
\text { Coeff }\end{array}$ & $\begin{array}{l}\text { rdized } \\
\text { ents }\end{array}$ & $\begin{array}{c}\text { Coefficie } \\
\text { nts }\end{array}$ & & \\
\hline & & & Std. & & & \\
\hline \multicolumn{2}{|c|}{ Model } & B & Error & Beta & $\mathrm{t}$ & Sig. \\
\hline \multirow[t]{4}{*}{1} & $\begin{array}{l}\text { (Constan } \\
\text { t) }\end{array}$ & 6.664 & 2.327 & & 2.864 & 0.006 \\
\hline & $\begin{array}{l}\text { Kompen } \\
\text { sasi }\end{array}$ & 0.193 & 0.086 & 0.287 & 2.241 & 0.029 \\
\hline & $\begin{array}{l}\text { Kompet } \\
\text { ensi }\end{array}$ & 0.423 & 0.081 & 0.572 & 5.217 & 0.000 \\
\hline & Motivasi & 0.217 & 0.091 & 0.302 & 2.374 & 0.021 \\
\hline
\end{tabular}

a. Dependent Variable: Produktivitas Kerja

\section{Adapun Model persamaan regresi}

berganda dari tabel diatas yaitu:

$$
Y=6,664+0,193 X_{1}+0,423 X_{2}-0,217 X_{3}
$$

Pada tabel 5 menjelaskan bahwa persamaan diatas, jika $\mathrm{X} 1, \mathrm{X} 2$ dan $\mathrm{X} 3=0$, maka nilai Y sebesar 6,664. Hal itu menunjukan jika kompensasi, kompetensi dan motivasi ditingkatkan akan memberikan produktivitas kerja yang makin baik dari pegawai PT Jasa Marga (Persero) Tbk Cabang Palikanci.

\section{Pengujian Hipotesis (Uji t)}

Hasil pada tabel 5 pada variabel kompensasi menunjukan nilai $t_{\text {hitung }}=2,241$ sedangkan nilai $t_{\text {tabel }}$ pada kebebasan $(\mathrm{dk})=56$ dan taraf signifikansi $\alpha=5 \%$ sebesar 2,003. Kemudian nilai p value kurang dari 0,05.
Maka berarti terdapat pengaruh kompensasi terhadap produktivitas kerja secara signifikan karena kriterianya terpenuhi yaitu 2,241> 2,003 dan $0,029<0,05$. Sehingga $\mathrm{H}_{0}$ ditolak dan $\mathrm{H}_{\mathrm{a}}$ diterima, dan hipotesis penelitian kesatu $\left(\mathrm{H}_{1}\right)$ yang diajukan diterima.

Pada variabel kompetensi nilai $t_{\text {hitung }}=$ 5,217 sedangkan nilai tabel pada kebebasan $(\mathrm{dk})=58$ dan taraf signifikansi $\alpha=5 \%$ sebesar 2,003. Kemudian nilai p value kurang dari 0,05. Hal ini berarti terdapat pengaruh Kompetensi terhadap Produktivitas Kerja secara signifikan karena 5,217> 2,003 dan $0,000<0,05$. Artinya $\mathrm{H}_{0}$ ditolak dan $\mathrm{H}_{\mathrm{a}}$ diterima, sehingga hipotesis penelitian kedua $\left(\mathrm{H}_{2}\right)$ diterima.

Motivasi nilai thitung $=2,374$ sedangkan nilai $\mathrm{t}_{\text {tabel }}$ pada kebebasan $(\mathrm{dk})=58$ dan taraf signifikansi $\alpha=5 \%$ sebesar 2,003. Sedangkan nilai $\mathrm{p}$ value kurang dari 0,05 . Artinya adalah terdapat pengaruh motivasi terhadap produktivitas kerja secara signifikan karena sudah terpenuhi kriterianya yaitu 2,374 > 2,003 dan 0,004 < 0,05. Maka $\mathrm{H}_{0}$ ditolak dan $\mathrm{H}_{\mathrm{a}}$ diterima, sehingga hipotesis penelitian ketiga $\left(\mathrm{H}_{3}\right)$ diterima.

\section{Uji F}

Uji F yang dilakukan bertujuan untuk mengetahui pengaruh variabel independent secara bersama-sama terhadap variabel 
Jurnal Manajemen dan Bisnis, Volume 3, No. 1, Juli 2021

dependen, yaitu variabel Kompensasi (X1), Kompetensi (X2) dan Motivasi (X3) terhadap variabel Produktivitas Kerja (Y).

Tabel 6. Uji F

ANOVA $^{b}$

\begin{tabular}{lcccccc}
\hline & & Sum of & & \multicolumn{2}{c}{ Mean } \\
Model & Squares & df & Square & F & Sig. \\
\hline 1 & $\begin{array}{l}\text { Regres } \\
\text { sion }\end{array}$ & 56.496 & 3 & 18.832 & 8.77 & $.000^{\mathrm{a}}$ \\
& & & & 2 & \\
& $\begin{array}{l}\text { Residu } \\
\text { al }\end{array}$ & 115.935 & 54 & 2.147 & & \\
$\quad$ & & & & & \\
$\quad$ Total & 172.431 & 57 & & & \\
\hline
\end{tabular}

a. Predictors: (Constant), Motivasi, Kompetensi, Kompensasi

b. Dependent Variable: Produktivitas Kerja Sumber : Hasil Output SPSS

Tabel 6 menunjukan p-value $0,000<$ 0,05 artinya signifikan sedangkan $\mathrm{F}$ hitung $8,772>2,767$ artinya signifikan $(\mathrm{df}=58-3$ = 55). Pengajuan hipotesis yang disusun hasilnya signifikan. Artinya ketiga variabel berpengaruh secara simultan atau bersamasama mempengaruhi produktivitas kerja PT Jasa Marga Cabang Palikanci. Maka hipotesis 4 diterima. Gambar 2 menjelaskan daerah ditolaknya Ho dan diterimanya $\mathrm{Ha}$

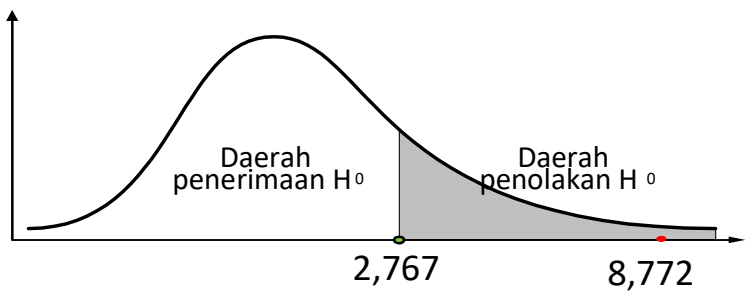

(Sianipar, 2020).
Gambar 2. Daerah Penerimaan dan Penolakan Uji F

\section{KESIMPULAN}

Dalam penelitian ini ditemukan pengaruh positif dan signifikan antara variabel kompensasi, kompetensi, dan motivasi terhadap variabel produktivitas kerja karyawan pada PT. Jasa Marga Persero Tbk. Cabang Palikanci. Sistem kompensasi yang diterapkan perusahaan ini masih belum cukup maksimal sehingga perlu adanya evaluasi besarnya kompensasi dan tambahan terkait dengan ini untuk pegawai PT. Jasa Marga Persero Tbk. Cabang Palikanci. Kompensasi yang diberikan harus sesuai dengan proporsi masing-masing. Begitu juga dengan kompetensi pegawai dapat ditingkatkan lagi dengan pelatihan khusus untuk menggali potensi yang optimal. Semangat kerja para pegawai juga perlu diperhatikan dengan cara mempererat lagi solidaritas antar pegawai agar dorongan sesama pegawai terjadi. Selain itu menciptakan lingkungan kerja yang harmonis dan nyaman penting juga sebagai motivasi bekerja sehingga dapat meningkatkan 
Jurnal Manajemen dan Bisnis, Volume 3, No. 1, Juli 2021

produktivitas kerja karyawan dan tujuan perusahaan mudah tercapai.

\section{DAFTAR PUSTAKA}

Aguk Sridaryono. (2019). Pengaruh

Kompetensi dan Kompensasi Terhadap

Kinerja Pegawai Negeri Sipil Melalui

Produktivitas Kerja Sebagai Variabel

Intervening di Politeknik Angkatan

Darat Malang. Sketsa Bisnis, 6(2), 99-

111.

https://doi.org/10.35891/jsb.v6i2.1705

Asneli, R., Haryani, D. S., \& Satriadi, S. (2018). Pengaruh Pemberian

Kompensasi Terhadap Produktivitas

Kerja Pegawai Pada Kantor Kecamatan

Tanjungpinang Kota. Jurnal Dimensi,

7(3), 563-571.

https://doi.org/10.33373/dms.v7i3.1713

Candra, A., \& Fatimah, F. (2020). Pengaruh Motivasi, Kompensasi Dan Kompetensi Terhadap Kinerja Pegawai Pengelola Kearsipan Yang Ada Di Lingkungan Pemerintah Kabupaten Ogan Komering Ilir. MOTIVASI: Jurnal Manajemen Dan Bisnis, 5(1), 814-825.

Dewi, I. R. (2020). Pengelolaan Keadilan

Distributif Terhadap Customer Affection Mitra Grab Karesidenan Banyumas. Jurnal Ekonomi Bisnis Dan Industri, 02(01), 13-20.

Djuhara, D. (2014). Pengaruh Motivasi Kerja Dan Kompetensi Terhadap Produktivitas Pada Karyawan Bagian Manajemen, Sirkulasi Dan Iklan Pt. Tribun Jabar Bandung. E-Jurnal STIE INABA, 13(1), 1-22.

Ngatemin, \& Arumwanti, W. (2019).
Pengaruh Kompetensi Dan Kompensasi Terhadap Motivasi Kerja Karyawan Hotel Di Kabupaten Karo Provinsi Sumatera Utara. Wave: Jurnal Ilmiah Teknologi Maritim, 12(September), 8092.

Oh, A., \& Novita, E. (2019). Pengaruh Kompetensi, Motivasi, Dan Kepuasan Kerja Terhadap Produktivitas Karyawan Pada Pt. Perindustrian Dan Perdagangan Bangkinang. Journal of Chemical Information and Modeling, 53(9), 1689-1699.

Peni, P. T., \& Suyoko, S. (2019). Terhadap Produktivitas Kerja Karyawan Divisi Operasional PT. Kamijaya Mitra Utama Tangerang. Jurnal Ilmu Administrasi Bisnis, 8(4), 1-7.

Rahayuningsih., S., \& Maelani., N. (2018). Pengaruh Kompetensi, Kompensasi dan Motivasi Terhadap Kinerja Karyawan ( Studi Pada PT . Pisma Garment Demak Jawa Tengah ). Prosiding Sendi, 726-736.

Santoni, N. P. C. C., \& Suana, I. W. (2018). Pengaruh Kompensasi, Motivasi, Disiplin Kerja Terhadap Produktivitas Kerja Karyawan Divisi Sales Di Honda Denpasar Agung. E-Jurnal Manajemen Universitas Udayana, 7(10), 5379. https://doi.org/10.24843/ejmunud.2018. v07.i10.p07

Sianipar, A. Z. (2020). PERBEDAAN

KEMAMPUAN PEMECAHAN MASALAH DAN KOMUNIKASI DAN PEMBELAJARAN LANGSUNG. 4(1), 14-20. Retrieved from http://journal.stmikjayakarta.ac.id/index .php/jisamar/article/download/167/136 